\title{
An Analytical Approach for the Optimal Operation of Simultaneous AC-DC Power Transmission System
}

\author{
Mohammad Tawhidul Alam ${ }^{1}$ and Q. Ahsan ${ }^{2}$ \\ ${ }^{1}$ Department of Electrical and Electronic Engineering, Daffodil International Univeristy, Bangladesh \\ ${ }^{2}$ Department of Electrical and Electronic Engineering, Green University of Bangladesh, Bangladesh
}

\begin{tabular}{l} 
Article Info \\
\hline Article history: \\
Received Mar 31, 2019 \\
Revised Mar 6, 2020 \\
Accepted Mar 24, 2020 \\
\hline
\end{tabular}

\section{Keyword:}

Simultaneous AC-DC system Objective function

Optimal point

Loadability and stability

improvement

Relative weight

\begin{abstract}
Simultaneous AC-DC power transmission technique can improve both loadability and stability of a power system with long transmission line. But, there is a tradeoff between loadability and stability, i.e. increase in the improvement of loadability causes the decrease in the improvement of stability and vice versa. Actually, it is a multi-objective optimization problem where the objective function depends on two decision variables with opposite in nature. Firstly, this paper presents an analytical expression for the objective function which is the function of two decision variables; power flowing capacity and critical clearing time. Secondly, a mathematical model is developed for the optimal point of the objective function. Considering a typical system a numerical analysis is performed using the proposed expressions. Again, the impacts of the line length and the voltage level of a transmission line on the objective function are also investigated. Finally, the developed model of the optimal point is validated to judge its accuracy and applied to a real system to justify its ability to evaluate the combined benefit of loadability and stability of simultaneous AC-DC system.
\end{abstract}

Copyright @ 2018 Institute of Advanced Engineering and Science. All rights reserved.

Corresponding Author:

Mohammad TawhidulAlam,

Department of Electrical and Electronic Engineering,

Daffodil International Univeristy,

Dhaka, Bangladesh.

Email: drtawhidul.eee@diu.edu.bd

\section{INTRODUCTION}

Load carrying capability of a long EHV transmission line is mainly limited by the steady state stability [1-2]. Moreover, it is required to keep sufficient margin against the transient stability. To improve the loadability and stability of an existing AC line present practices are the use of series capacitive compensation [3-5] and FACTS devices [6-8]. A new approach of power transmission, where DC is allowed to flow through the AC line simultaneously, can be a solution to improve the performance of existing transmission system. The main benefit of simultaneous AC-DC system is that it can improve both loadability [9-11] and stability [12-14].

An appropriate mathematical model is developed in [15] for the loadability analysis of simultaneous AC-DC system. In this model, AC and DC power of AC-DC system are expressed in terms of AC power flow of original AC system. The work of the paper clearly shows that the higher amount of power flow cannot be achieved in all operating conditions. Using the mathematical model, the limiting values of the variables of any system can be determined for which the improvement in loadability is just marginally possible. From the numerical analysis of [15] it is seen that the power flow increases with the increase of voltage mix and transmission angle.

An elaborate numerical analysis of power flow through simultaneous AC-DC system is presented in [9]. This analysis shows the power flow variation with the change of transmission angle for a fixed DC 
voltage mix. It is observed that the power flow increases with the increase of transmission angle at a certain level and beyond which power flow decreases with the increase of transmission angle.

A mathematical model for the stability analysis of simultaneous AC-DC system is shown in [16]. The model is based on the equal area criterion of stability analysis and it can handle only the severe most fault of transmission line. Stability analysis of simultaneous AC-DC system is a bit complex task. To reduce this complexity, K.P Basu [17] proposed a new approach where the AC-DC composite system is treated as a pure DC system by turning off the circuit breakers of AC power flow of this system as soon as the fault is cleared.

H. Rahman and B.H. Khan [12] presented a clear-cut comparison of stability between the simultaneous AC-DC transmission line and series compensated original AC transmission line. They have shown that the simultaneous AC-DC system is better than series compensated AC system in stability point of view.

Although simultaneous AC-DC system can improve loadability and stability it is also found that all the works in the literature either on loadability or on stability improvement. But, no work has yet been found on the combined improvement. Therefore, it is necessary to find out an optimal operating point of a system where the loadability and stability both can be improved at a reasonable level.

The problem where the ultimate goal is a function of more than one variable of conflicting in nature is called multi-objective problem. A solution of radio frequency (RF) circuit sizing optimization has been presented in [18] where the problem is subdivided into two parts. One is the normalization of the objective function and other one is the assignment of weights to the objectives. Multi-objective optimization problems have many Pareto solutions and decision is made among them cosidering the total balance over all the objectives taking into account. The totally balancing over criteria is usually called trade-off. H. Nakayama et al. discussed the different approaches of trade-off in [19]. It also mentioned the difficulty in weighting method and provides a way to overcome this difficulty.

In solving multiobjective problems, decision maker may be interested in a set of Pareto optimal points instead of single point. Genetic algorithm (GA) can be used to solve multi-objective problems as it works with a population of points. N. Srinivas and K. Deb [20] investigated Goldbergs's notation of non dominated sorting in GAs along with niche and specification method to find multiple pareto-optimal points simultaneously. The performance of evolutionary algorithm (EA) and conventional gradient based method are demonstrated in [21] for finding Pareto fronts. It also shows the application of multi-objective algorithm in an analytical test problem as well as real-world problems.

It is evident that the higher the improvement in loadability the lower the improvement in stability and vice versa. Therefore, the loadability and stability improvements at a time is a multi-objective problem. This paper presents an analytical model for the combined improvement of loadability and stability of simultaneous AC-DC system through weighted sum multiobjective optimization approach.

\section{PROPOSED MODEL}

The main purpose of simultaneous AC-DC system is to improve loadabiliy and stability both. The equations (1) and (3) present the expressions of loadability [15] and stability [16], respectively.

$$
\begin{gathered}
P_{c o m b}=[(1-k) \beta+\sqrt{2} k \gamma] P_{l} \\
o r \quad f_{1}=[(1-k) \beta+\sqrt{2} k \gamma] P_{l} \\
T_{C R}=T_{c r} \sqrt{\left(1-\frac{P_{c o m b}}{\left(P_{D C p f}+\bar{P}_{a c m}\right)}\right)\left(\frac{\delta_{m}-\delta_{a c}}{\delta_{c r}-\delta_{0}}\right) \frac{P_{l}}{P_{c o m b}}} \\
\text { or } f_{2}=T_{c r} \sqrt{\left(1-\frac{P_{c o m b}}{\left(P_{D C p f}+\bar{P}_{a c m}\right)}\right)\left(\frac{\delta_{m}-\delta_{a c}}{\delta_{c r}-\delta_{0}}\right) \frac{P_{l}}{P_{c o m b}}}
\end{gathered}
$$

Where, $P_{\text {comb }}$ and $T_{C R}$ are represented by $f_{1}$ and $f_{2}$ in equations (2) and (4) respectively.

Generally loadability, $f_{l}$, and stability, $f_{2}$, are reciprocal in nature. That is, if a system is operated at higher loadability the stability margin will be lower. It is desirable to maximize both the objectives but due to trade off it is not possible to get both of them at their highest levels. There are several methods available for solving this kind of multi-objective optimization problem and among them weighted sum approach is used in this work [18-19]. As the stability and loadabiliy both are to be increased the objective function $\mathrm{Z}$ may be expressed as 
$Z=\sum_{i=1}^{N} W_{i} \bar{f}_{i}$

$$
Z^{*}=\operatorname{Max} \sum_{i=1}^{N} W_{i} \bar{f}_{i}
$$

Subject to

$$
\sum_{i=1}^{N} W_{i}=1
$$

$W_{i}>0$

Where,

$$
\bar{f}_{i}^{(L)} \leq \bar{f}_{l} \leq \bar{f}_{i}^{(U)}
$$

$N=$ Number of decision variables, $i=1,2, \ldots . . N$

$W_{i}=$ Relative weight of $i_{t h}$ decision variable

$\bar{f}_{i}=$ Normalized value of $i_{t h}$ decision variable $f_{i}$

$Z^{*}=$ Maximum value of the objective function

$f_{i}^{(L)}$ and $f_{i}^{(U)}$ indicates the upper and lower bound of the $i_{t h}$ decision variable.

As there are only two objectives in this work i.e. loadability and stability the value of $N$ is 2 and the objective function $Z$ becomes

$Z=W_{1} \bar{f}_{1}+W_{2} \bar{f}_{2}$

Where,

$W_{1}=$ Relative weight for loadability

$W_{2}=$ Relative weight for critical clearing time (stability)

The normalization of the decision variables can found as

$$
\begin{aligned}
\bar{f}_{1}(k, \beta, \gamma) & =\frac{f_{1}-f_{1}^{\text {min }}}{f_{1}^{\text {max }}-f_{1}^{\min }} \\
& =\bar{P} \\
& =\frac{P_{\text {comb }}-P_{\min }}{P_{\max }-P_{\min }}
\end{aligned}
$$

$$
\begin{aligned}
\bar{f}_{2}(k, \beta, \gamma) & =\frac{f_{2}-f_{2}^{\text {min }}}{f_{2}^{\text {max }}-f_{2}^{\text {min }}} \\
& =\bar{T} \\
& =\frac{T_{C R}-T_{\min }}{T_{\max }-T_{\min }}
\end{aligned}
$$

Where,

$\bar{P}=$ Normalized value of Loadability

$\bar{T}=$ Normalized vale of critical clearing time

The equation (3) for $T_{C R}$ can be written in the following simplified form

$$
T_{C R}=M \sqrt{\left(\frac{1}{P_{\text {comb }}}-\zeta\right)}
$$

Where,

$$
\begin{aligned}
& M=T_{c r} \sqrt{\left(\frac{\delta_{m}-\delta_{a c}}{\delta_{c r}-\delta_{0}}\right) P_{l}} \\
& \zeta=\frac{1}{\left(P_{D C p f}+\bar{P}_{a c m}\right)}
\end{aligned}
$$

Now the equation (9) becomes

$\bar{f}_{2}=\frac{M \sqrt{\left(\frac{1}{P_{\text {comb }}}-\zeta\right)}-T_{\min }}{T_{\max }-T_{\min }}$ 
To evaluate the weighted sum of this optimization system the relative weight approach is utilized. Relative weights reflect the relative importance of the objectives. For example, if 1 unit gain in objective-1 can be compensated by two unit lose in objective-2, then the relative weight of objective- 1 will be 2 while the relative weight of objective- 2 will be 1 . If the objectives are normalized and summation of all the weights is 1 (one) then the relative weights must be out of 1 (one). The calculation of relative weights for stability and loadability are elaborately shown below.

$$
W_{2}=\frac{1}{1-\frac{d \bar{T}}{d \bar{P}}}
$$

Where, $\frac{d \bar{T}}{d \bar{P}}=\frac{P_{\max }-P_{\min }}{T_{\max }-T_{\min }} \frac{d T_{C R}}{d P_{\text {comb }}}$

$$
\begin{aligned}
& =\frac{P_{\text {max }}-P_{\text {min }}}{T_{\max }-T_{\min }} \frac{d}{d P_{c o m b}}\left(M \sqrt{\left(\frac{1}{P_{c o m b}}-\zeta\right)}\right) \\
& =\frac{-M}{2 \Delta P_{c o m b}^{2} \sqrt{\frac{1}{P_{c o m b}}-\zeta}}
\end{aligned}
$$

Where, $\Delta=\frac{T_{\max }-T_{\min }}{P_{\max }-P_{\min }}$

Now the equation (12) can be written as follows

$$
W_{2}=\frac{1}{1+\frac{M}{2 \Delta P_{c o m b}^{2} \sqrt{\frac{1}{P_{c o m b}}-\zeta}}}
$$

As the summation of all the weights is 1 (one) and there are only two objectives in this optimization process, the other weight can be written in the following way.

$$
\begin{aligned}
& W_{1}=1-W_{2} \\
& =1-\frac{1}{1+\frac{M}{2 \Delta P_{c o m b}^{2} \sqrt{\frac{1}{P_{c o m b}}-\zeta}}}
\end{aligned}
$$

Combining the equations (8), (11), (14) and (15) the objective function, $\mathrm{Z}$, presented in equation (7) can be expressed as

$$
\begin{aligned}
& Z=\left(1-\frac{1}{1+\frac{M}{2 \Delta P_{c o m b}^{2} \sqrt{\frac{1}{P_{c o m b}}-\zeta}}}\right) \frac{P_{c o m b}-P_{\min }}{P_{\max }-P_{\min }}+\left(\frac{1}{1+\frac{M}{2 \Delta P_{c o m b}^{2} \sqrt{\frac{1}{P_{c o m b}}-\zeta}}}\right) \frac{M \sqrt{\left(\frac{1}{P_{c o m b}}-\zeta\right)}-T_{\min }}{T_{\max }-T_{\min }} \\
& =\frac{P_{c o m b}-P_{\min }}{P_{\max }-P_{\min }}+\frac{1}{1+\frac{M}{2 \Delta P_{c o m b}^{2} \sqrt{\frac{1}{P_{c o m b}}-\zeta}}}\left(\frac{M \sqrt{\left(\frac{1}{P_{c o m b}}-\zeta\right)}-T_{\min }}{T_{\max }-T_{\min }}-\frac{P_{c o m b}-P_{\min }}{P_{\max }-P_{\min }}\right)
\end{aligned}
$$

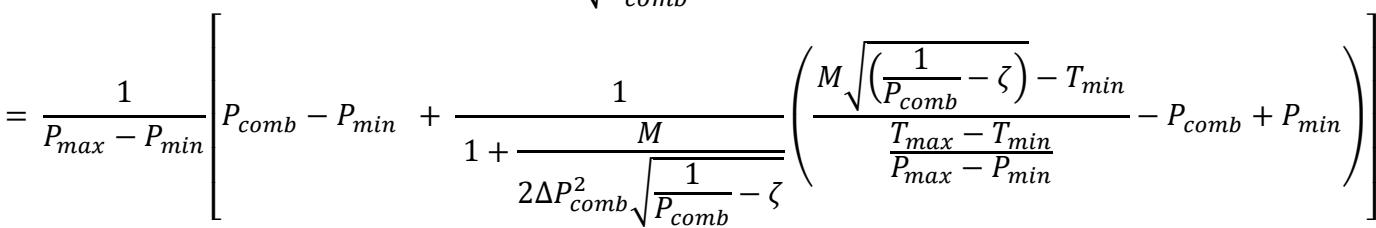

$$
\begin{aligned}
& =\frac{1}{P_{\max }-P_{\min }}\left[P_{c o m b}-P_{\min }+\frac{1}{1+\frac{M}{2 \Delta P_{c o m b}^{2} \sqrt{\frac{1}{P_{c o m b}}-\zeta}}}\left(\frac{M \sqrt{\left(\frac{1}{P_{c o m b}}-\zeta\right)}}{\Delta}-\frac{T_{\min }}{\Delta}-P_{c o m b}+P_{\min }\right)\right]
\end{aligned}
$$




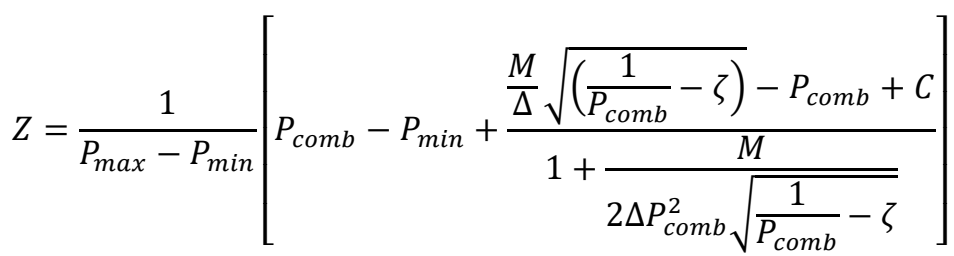

Where, $C=P_{\min }-\frac{T_{\min }}{\Delta}$

The equation (16) is the analytical expression for the objective function of simultaneous AC-DC power flow where the impacts of the loadability and stability both are incorporated.

To get the optimum point or maximum value of the objective function, $Z$, the equation (16) need to be differentiated with respect to $P_{\text {comb }}$ and equated it to zero. i.e. $\frac{d Z}{d P_{\text {comb }}}=0$.

Now,

$$
\frac{d Z}{d P_{c o m b}}=1+\frac{\left(1+\frac{M}{2 \Delta P_{c o m b}^{2} \sqrt{\frac{1}{P_{c o m b}}-\zeta}}\right)\left(\frac{-M}{2 \Delta P_{c o m b}^{2} \sqrt{\frac{1}{P_{c o m b}}-\zeta}}-1\right)-\left(\frac{M}{\Delta} \sqrt{\frac{1}{P_{c o m b}}-\zeta}-P_{c o m b}+C\right) \frac{d}{d P}\left(\frac{M}{2 \Delta P_{c o m b}^{2} \sqrt{\frac{1}{P_{c o m b}}-\zeta}}\right)}{\left[1+\frac{M}{2 \Delta P_{c o m b}^{2} \sqrt{\frac{1}{P_{c o m b}}-\zeta}}\right]}
$$

Or

$$
=0
$$

$$
\begin{gathered}
-\left(1+\frac{M}{2 \Delta P_{c o m b}^{2} \sqrt{\frac{1}{P_{c o m b}}-\zeta}}\right)\left(1+\frac{M}{2 \Delta P_{c o m b}^{2} \sqrt{\frac{1}{P_{c o m b}}-\zeta}}\right)-\left(\frac{M}{\Delta} \sqrt{\frac{1}{P_{c o m b}}-\zeta}-P_{c o m b}+C\right) \frac{d}{d P_{c o m b}}\left(\frac{M}{2 \Delta P_{c o m b}^{2} \sqrt{\frac{1}{P_{c o m b}}-\zeta}}\right) \\
=-\left(1+\frac{M}{2 \Delta P_{c o m b}^{2} \sqrt{\frac{1}{P_{c o m b}}-\zeta}}\right)^{2}
\end{gathered}
$$

Or

$$
\left(\frac{M}{\Delta} \sqrt{\frac{1}{P_{c o m b}}-\zeta}-P_{c o m b}+C\right) \frac{d}{d P_{c o m b}}\left(\frac{M}{2 \Delta P_{c o m b}^{2} \sqrt{\frac{1}{P_{c o m b}}-\zeta}}\right)=0
$$

The solution of equation (17) can be obtained in the following way

$$
\begin{gathered}
\frac{M}{\Delta} \sqrt{\frac{1}{P_{c o m b}}-\zeta}-P_{c o m b}+C=0 \\
\text { or } \quad P_{c o m b}-C=\frac{M}{\Delta} \sqrt{\frac{1}{P_{c o m b}}-\zeta} \\
\text { or } \quad\left(P_{c o m b}-C\right)^{2}=\left(\frac{M}{\Delta}\right)^{2}\left(\frac{1}{P_{c o m b}}-\zeta\right) \\
\text { or } P_{c o m b}^{2}-2 P_{c o m b} C+C^{2}=K\left(\frac{1-\zeta P_{c o m b}}{P_{c o m b}}\right)
\end{gathered}
$$

Where,

$$
K=\left(\frac{M}{\Delta}\right)^{2}
$$

Equation (19) can be rearranged as

$$
\begin{aligned}
& P_{c o m b}^{3}-2 P_{c o m b}^{2} C+C^{2} P_{c o m b}=K-K \zeta P_{c o m b} \\
& P_{c o m b}^{3}+(-2 C) P_{c o m b}^{2}+\left(K \zeta+C^{2}\right) P_{c o m b}+(-K)=0
\end{aligned}
$$

Now the solution of equation (20) is as follows:

$$
P_{c o m b}=\frac{1}{3}\left(2 C-R-\frac{D_{0}}{R}\right)
$$


Where,

$$
\begin{aligned}
& R=\sqrt[3]{\frac{D_{1}+\sqrt{D_{1}^{2}-4 D_{0}^{3}}}{2}} \\
& D_{0}=C^{2}-3 K \zeta \\
& D_{1}=2 C^{3}+18 C K \zeta-27 K
\end{aligned}
$$

The equation (21) is the analytical expression for combined power flow for which the value of the objective function would be maximum i.e. both the objectives, loadability and stability, can be improved optimally.

\section{NUMERICAL ANALYSIS}

The numerical analysis of the objective function and its optimal point are presented in this section. It is true that there is no scope to achieve very high amount of combined improvement of loadability and stability. More precisely, it can be said that if someone want to achieve very high amount of loadability improvement he has to lose the stability improvement and vice versa. In this regard, to clarify the proposed model a typical single circuit transmission system is considered in this section which is presented in Figure 1.

This power system has a long transmission line with a generation capacity of 1100MVA. The length of the line is $400 \mathrm{~km}$ and the voltage of the line is $345 \mathrm{kV}$. Basically this transmission system is evacuating power from $132 \mathrm{kV}$ generator bus to a distant infinite bus of $132 \mathrm{kV}$. Now the the pure AC system is converted into simultaneous AC-DC system and it is shown in Figure 2. The the numerical values of all the parameters from generator to infinite bus for pure AC and for simultaneous AC-DC system are presented in Appendix-A.

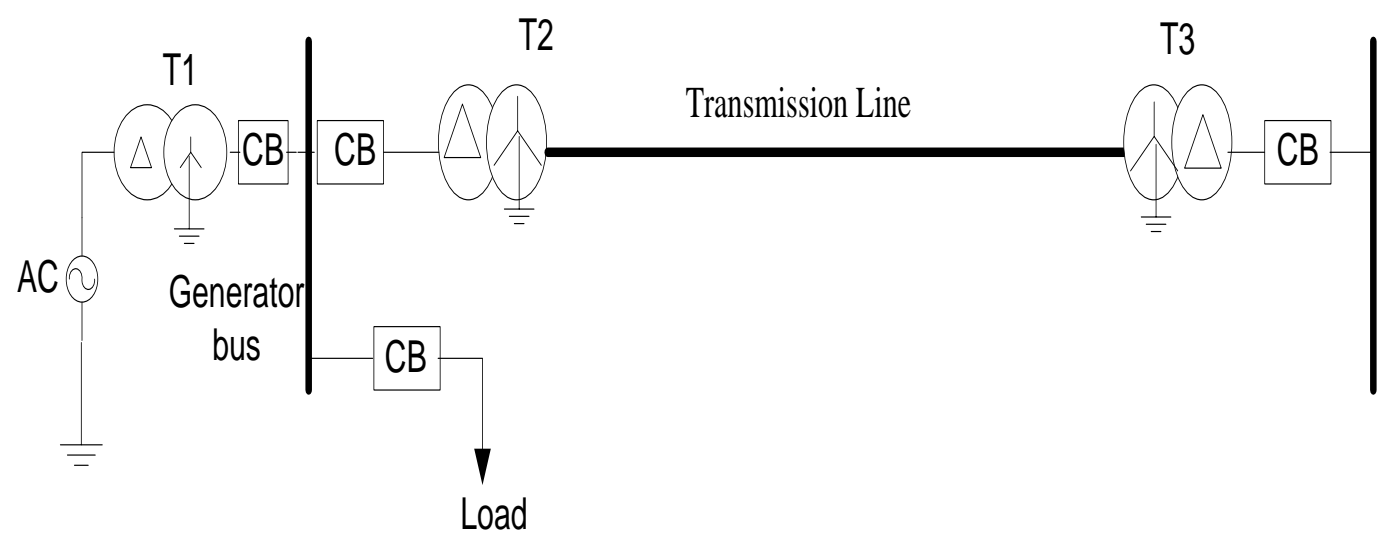

Figure 1.Single circuit AC power transmission system

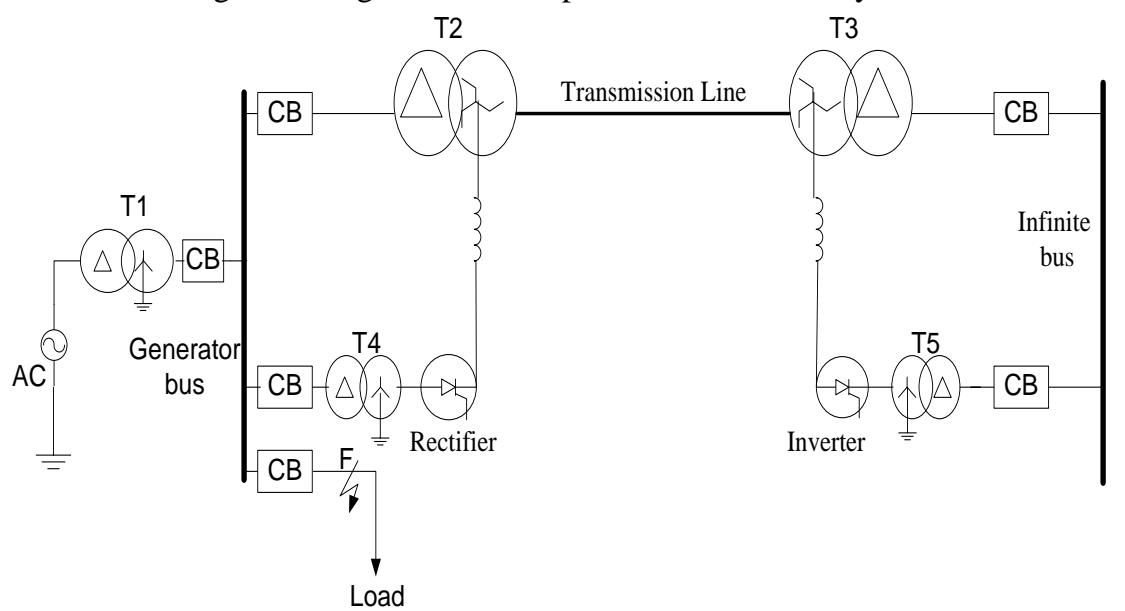

Figure 2. Simultaneous AC-DC power transmission system 


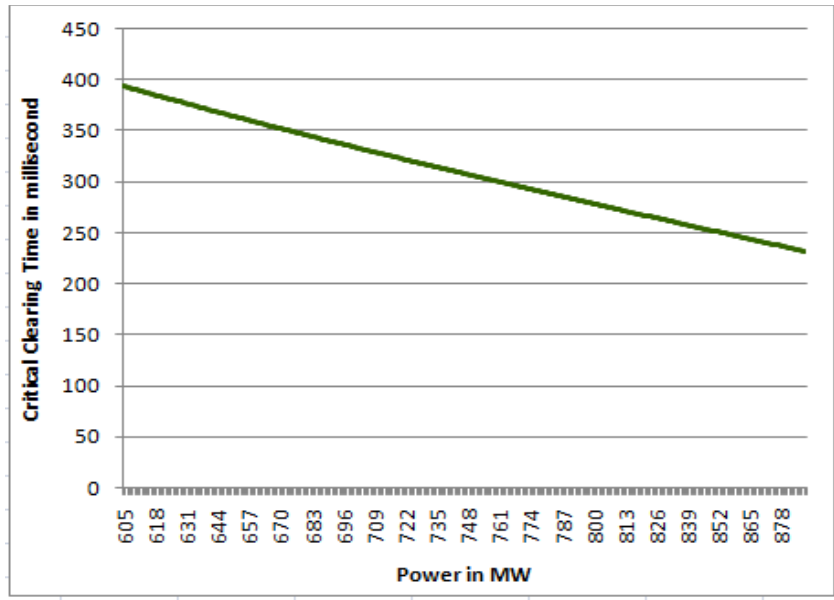

Figure 3. Stability versus loadability

Using the numerical data presented in Appendix-A, initially the loadability and stability analysis is performed for pure AC system. The steady state loadability of pure AC system is found as 605MW considering $30 \%$ steady state stability margin. Incase of stability analysis a 3-phase to ground fault is considered at the load terminal and obtained critical clearing time (CCT) is of $231 \mathrm{~ms}$. Considering $605 \mathrm{MW}$ and $231 \mathrm{~ms}$ as base values for the operation of simultaneous AC-DC system the stability analysis is performed for the same type of fault with different values of steady state power. In this case, obtained CCT is of $380 \mathrm{~ms}$ for $605 \mathrm{MW}$ of steady state loading and $231 \mathrm{~ms}$ for $898 \mathrm{MW}$ of steady state loading. The detail analysis is shown in Figure 3.

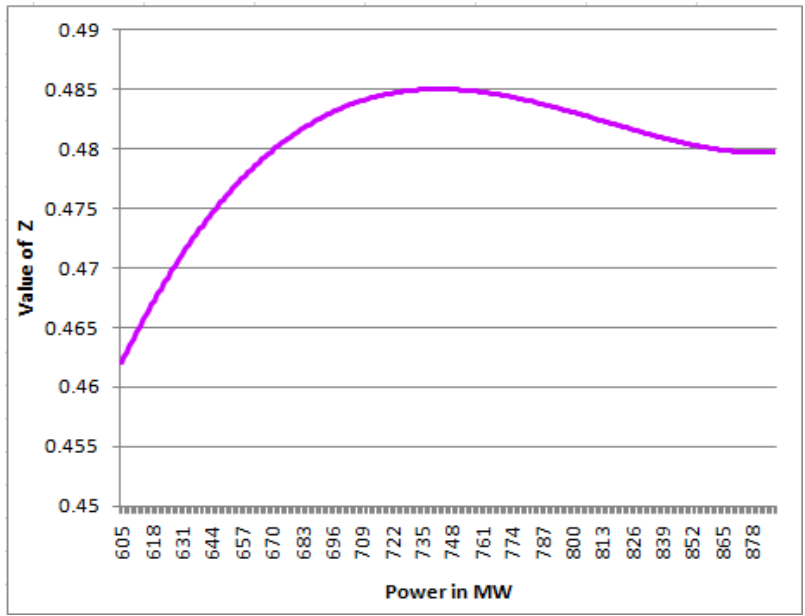

Figure 4. Objective function variations with respect to combined power flow

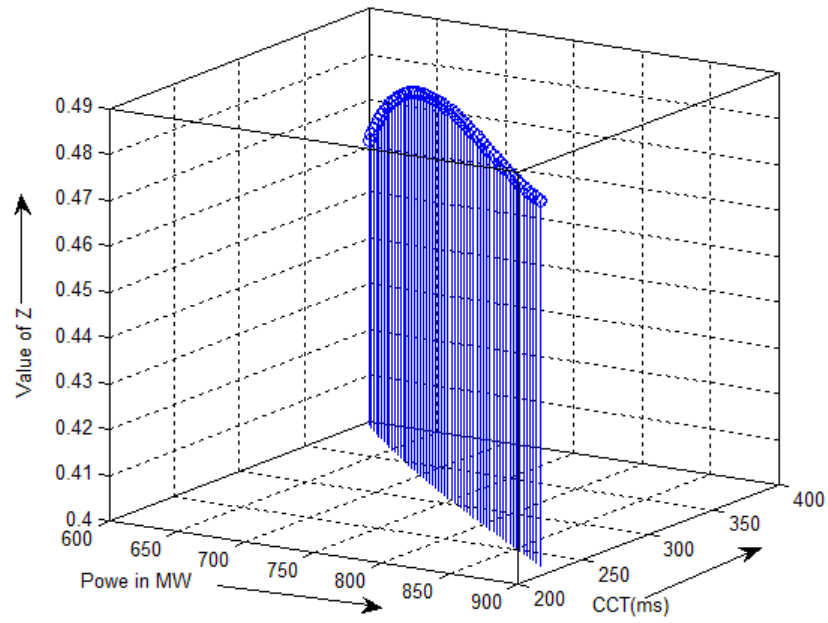

Figure 5. Objectives function with respect to power flow and CCT 
It is seen from the Figure 3 that the minimum loadability point gives maximum stability (CCT) and maximum loadability point gives minimum stability. To obtain the improvements in both loadability and stability in the considered system at a time the analytical expression (16) is used and the objective function, $\mathrm{Z}$, found from the numerical data is shown in Figure 4. The objective function $\mathrm{Z}$ is mainly the combined improvement of loadability and stability. In this figure the variation of objective function is shown with respect the variation in combined power flow. It is clearly observed that the value of $\mathrm{Z}$ is initially increasing in nature with the increase of combined power flow and for a particular value of combined power it has a steady state value and further increase of combined power flow gives the decreasing value of $\mathrm{Z}$. As the objective is to find the maximum value of the objective function $\mathrm{Z}$ the steady state value of $\mathrm{Z}$ in Figure 4 is the maximum value. To get an overall picture of the objective function with respect to both the decision variables; loadability and stability, a 3-D plot is presented in Figure 5.

The main objective of this optimization process in this paper is to find the value of combined power flow for which the objective function would be maximum. Applying the equation (21) in this considred system it is found that the maximum value of the objective function of this particular system occurs at $742 \mathrm{MW}$ of loading and at this loading the CCT of the system is is of $313 \mathrm{~ms}$. This point is actually the desired optimal operating point of this system where the objective function is maximum. Therefore, it can be said that at the optimal operating point of this particular system the loadability and stability improvements are $22.65 \%$ and $35.5 \%$ respectively.

To investigate the impacts of the line voltage and line length of a transmission system on this optimal point two different analysis are performed. One, changing the voltage of this considred system keeping the other parameters unchanged and other one, changing the line length keeping the other parameters same as their original value. The impact of voltage change on the optimal point is presented in Figure 6.

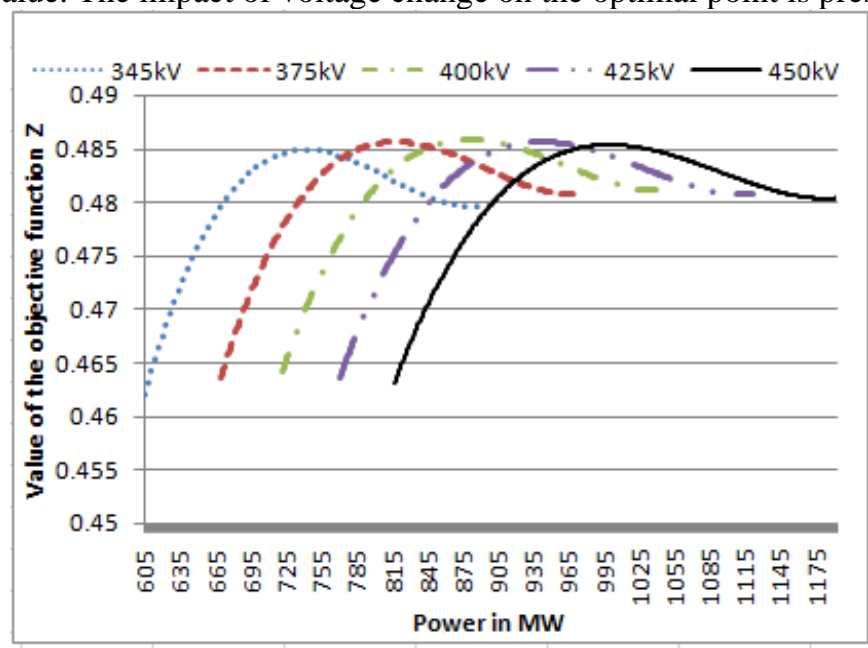

Figure 6. Impact of voltage change on the optimal point

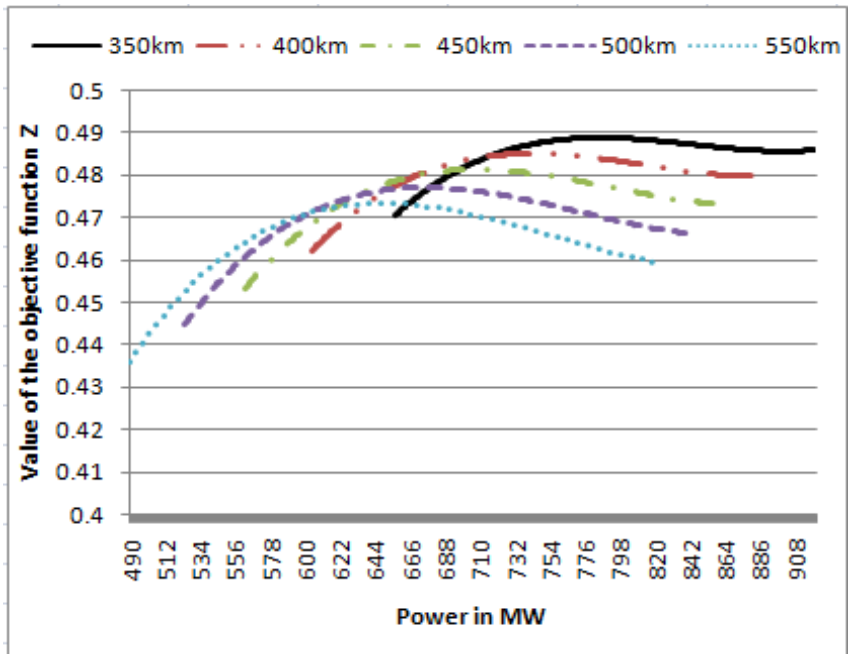

Figure 7. Impact of the line length on the optimal point 
Figure 6 clearly reveals that the optimal point shifted from lower loadability to higher loadability with the increase of voltage level of the system. That is, a system with higher voltage level has higher power carrying capacity at its optimal operating point and a system with lower voltage level has the lower power carrying capacity at its optimal operating point point.

The impact of the change of line length on the optimal point is presented in Figure 7. It is clearly observed that the optimal points moving towards the lower loadability from the higher loadability with the increase of line length of the system. That is, the longer the transmission line the lower the load carrying capability at its optimal point.

Now, using equation (21) the power flow at the optimal operating point for the considered system, changing the voltage level and line length, are evaluated and presented in Table 1 . The $3 \mathrm{rd}$ and $6^{\text {th }}$ columns of the table present the power flow at the optimal operating point of simultaneous AC-DC systemand the $2^{\text {nd }}$ and $5^{\text {th }}$ columns of the table also show the power flow through pure AC system for different voltage level and line length respectively. Note that the power flow in pure AC system is calculated considering the recommended loadability margin for the long transmission line [1].

\begin{tabular}{cccccc} 
Table 1. Optimal Power Flow in Comparison With Original AC Power Flow \\
\hline \multicolumn{3}{c}{ Change of voltage level } & \multicolumn{3}{c}{ Change of line length } \\
\hline $\begin{array}{c}\text { Voltage } \\
(\mathrm{kV})\end{array}$ & $\begin{array}{c}\text { Power flow } \\
\text { in pure AC } \\
\text { system } \\
\text { (MW) }\end{array}$ & $\begin{array}{c}\text { Power flow in AC- } \\
\text { DC system at the } \\
\text { optimal point (MW) }\end{array}$ & $\begin{array}{c}\text { Line } \\
\text { length } \\
(\mathrm{km})\end{array}$ & $\begin{array}{c}\text { Power flow } \\
\text { in pure AC } \\
\text { system } \\
\text { (MW) }\end{array}$ & $\begin{array}{c}\text { Power flow in } \\
\text { the optimal } \\
\text { point(MW) }\end{array}$ \\
\hline 345 & 605 & 742 & 350 & 657 & 787 \\
375 & 670 & 818 & 400 & 605 & 742 \\
400 & 723 & 882 & 450 & 562 & 708 \\
425 & 771 & 942 & 500 & 524 & 676 \\
450 & 818 & 100 & 550 & 490 & 648 \\
\hline
\end{tabular}

From Table 1 it is clearly observed that the power flow at the optimal operating point of simultaneous AC-DC system at any voltage level and line length is much higher than that of its pure AC system. Although the stability margins (CCTs) at the optimal operating point of the simultaneous AC-DC system have not been mentioned in the table but there will be significant increase in stability margin.

The improvements of loadability and stability of simultaneous AC-DC system at the optimal points, in comparison with that of pure AC system, for different line length and voltage level are presented in Figures 8 and 9 respectively. It is seen that the stability improvement (SI) is higher than the loadability improvement (LI) at the optimal points for the change of voltage and line length both. In case of change in line length the LI and SI both are increasing in nature with the increase in the length of transmission line. On the contrary, the LI and SI both have approximately constant magnitude at the optimal points for all voltage levels. It is also seen from Figure 8 that the difference between the magnitude of LI and SI decreases with the increase of line length.

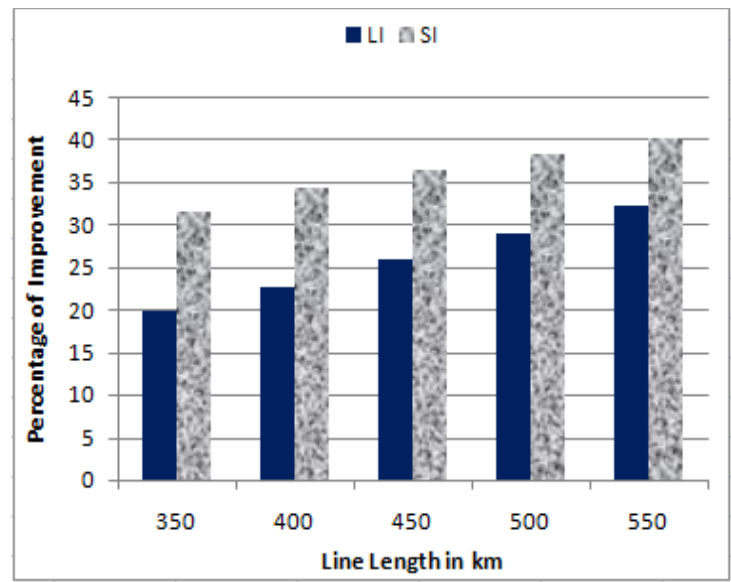

Figure 8. Comparison of LI and SI for the change of line length at the optimal point 


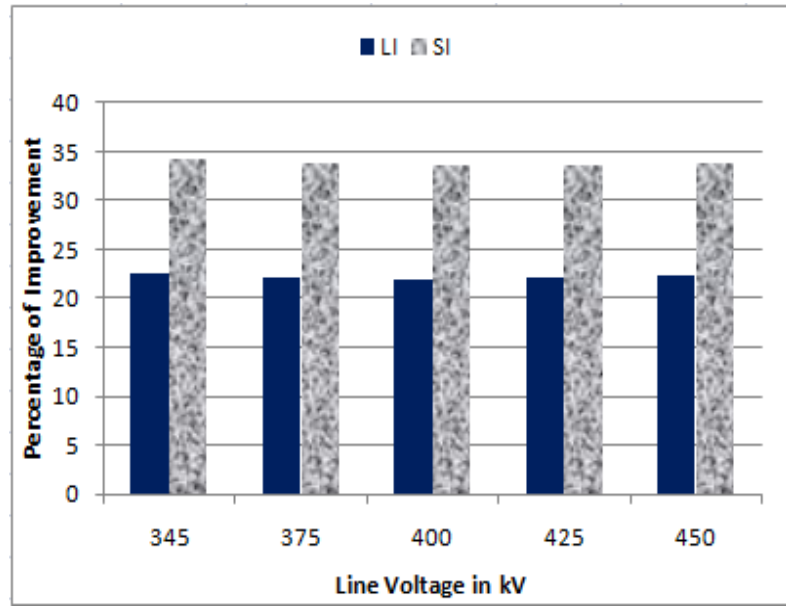

Figure 9. Comparison of LI and SI for the change of line voltageat the optimal point

\section{VALIDATION OF THE DEVELOPED MODEL}

The mdel which developed for the optimal operation of simultaneous AC-DC system in section 2 is validated in this section. A power system with its numerical data is considered for this validation. The validation is performed comparing the results obtained through developed model with those obtained through MATLAB simulation. The considered power system is presented in Figure 10.

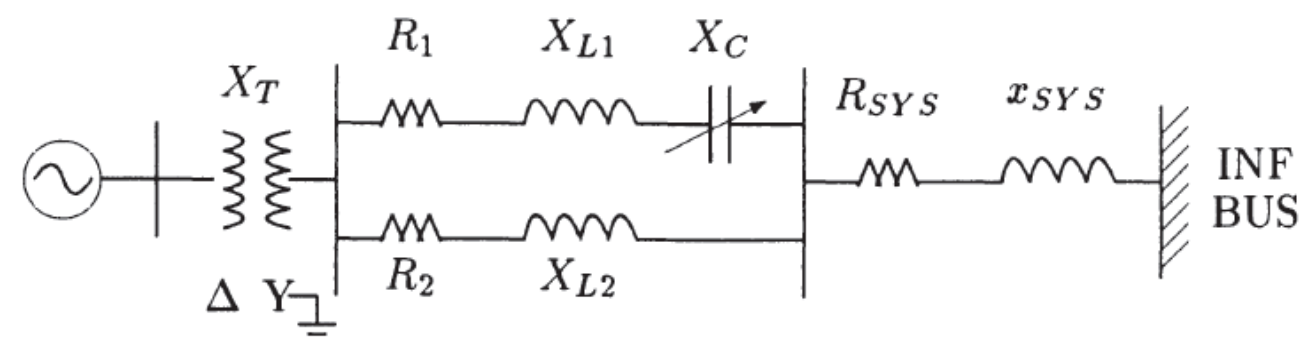

Figure 10. IEEE second benchmark system

The system presented in Figure 10 is a $500 \mathrm{kV}$ double circuit transmission system. The system parameters are presented in Table 2 . In this analysis all the resistances and capacitive compensation of the system are neglected.

Table 2. Network impedance in per unit based on 100 MVA

\begin{tabular}{ccc}
\hline Parameter & Positive sequence & Zero sequence \\
\hline$R_{T}$ & 0.0002 & 0.0002 \\
$X_{T}$ & 0.02 & 0.02 \\
$R_{I}$ & 0.0074 & 0.022 \\
$X_{L 1}$ & 0.08 & 0.24 \\
$R_{2}$ & 0.0067 & 0.0186 \\
$X_{L 2}$ & 0.0739 & 0.21 \\
$R_{s y s}$ & 0.0014 & 0.0014 \\
$X_{s y s}$ & 0.03 & 0.03 \\
\hline
\end{tabular}

The AC system is converted into simultaneous AC-DC system and initially MATLAB simulation is performed for the optimal operation of the system and then the developed model is applied to the system. The results of MATLAB simulation and developed model are compared and presented in Table 3 and Table 4. The comparison is shown in Table 3 and Table 4 considering different DC voltage level and different transmission angle respectively. 
Table 3. Results comparison between MATLAB Simulation and developed model with changing the DC voltage level

\begin{tabular}{ccccccc}
\hline $\begin{array}{c}\text { \% of DC } \\
\text { voltage } \\
\text { mix }\end{array}$ & $\begin{array}{c}\text { Loadability } \\
\text { developed } \\
\text { model }\end{array}$ & $\begin{array}{c}\text { Through } \\
\text { MATLAB } \\
\text { simulation }\end{array}$ & $\begin{array}{c}\text { Difference } \\
(\%)\end{array}$ & $\begin{array}{c}\text { Through } \\
\text { developed } \\
\text { model }\end{array}$ & $\begin{array}{c}\text { Through } \\
\text { MATLAB } \\
\text { simulation }\end{array}$ & $\begin{array}{c}\text { Difference } \\
(\%)\end{array}$ \\
\hline 20 & $842 \mathrm{MW}$ & $846 \mathrm{MW}$ & 0.47 & $175.86 \mathrm{~ms}$ & $175.02 \mathrm{~ms}$ & -0.48 \\
30 & $928 \mathrm{MW}$ & $931 \mathrm{MW}$ & 0.32 & $179.22 \mathrm{~ms}$ & $178.71 \mathrm{~ms}$ & -0.28 \\
49.5 & $1050 \mathrm{MW}$ & $1051 \mathrm{MW}$ & 0.095 & $182.3 \mathrm{~ms}$ & $182.14 \mathrm{~ms}$ & -0.087 \\
\hline
\end{tabular}

It is clearly observed from Table 3 and Table 4 that the loadability and stability obtained through developed model are very much close to those obtained from MATLAB simulation at the optimal operating point. The tables also reveal that the magnitude of differences between these two approaches in case of loadability and stability are less than $0.5 \%$ which indicates the acuuracy level of the model is extremely high.

Table 4. Results comparison between MATLAB Simulation and developed model with changing the transmission angle

\begin{tabular}{ccccccc}
\hline \multirow{2}{*}{$\begin{array}{c}\text { Transmission } \\
\text { angle }\end{array}$} & $\begin{array}{c}\text { Loadability } \\
\text { Through } \\
\text { developed } \\
\text { model }\end{array}$ & $\begin{array}{c}\text { Through } \\
\text { MATLAB } \\
\text { simulation }\end{array}$ & $\begin{array}{c}\text { Difference } \\
(\%)\end{array}$ & $\begin{array}{c}\text { Through } \\
\text { developed } \\
\text { model }\end{array}$ & $\begin{array}{c}\text { Through } \\
\text { MATLAB } \\
\text { simulation }\end{array}$ & $\begin{array}{c}\text { Difference } \\
(\%)\end{array}$ \\
\hline 20 & $1100 \mathrm{MW}$ & $1101 \mathrm{MW}$ & 0.09 & $191.23 \mathrm{~ms}$ & $191.1 \mathrm{~ms}$ & -0.068 \\
30 & $1081 \mathrm{MW}$ & $1081 \mathrm{MW}$ & 0 & $187.49 \mathrm{~ms}$ & $187.49 \mathrm{~ms}$ & 0 \\
50 & $1036 \mathrm{MW}$ & $1037 \mathrm{MW}$ & 0.096 & $179.9 \mathrm{~ms}$ & $179.7 \mathrm{~ms}$ & -0.11 \\
\hline
\end{tabular}

\section{APPLICATION OF THE ANALYTICAL MODEL OF OPTIMAL POINT}

To judge the applicability of the proposed model a $500 \mathrm{kV}, 804 \mathrm{~km}$ long transmission system is considered. In this transmission system power is evacuated from Colstrip (eastern Montana) to Taft. The Montana generation system has four generating units with a total capacity of 2272MW. The circuit model of the system is presented in Figure 11[22] anda detail description of the system is presented in Appendix-B.

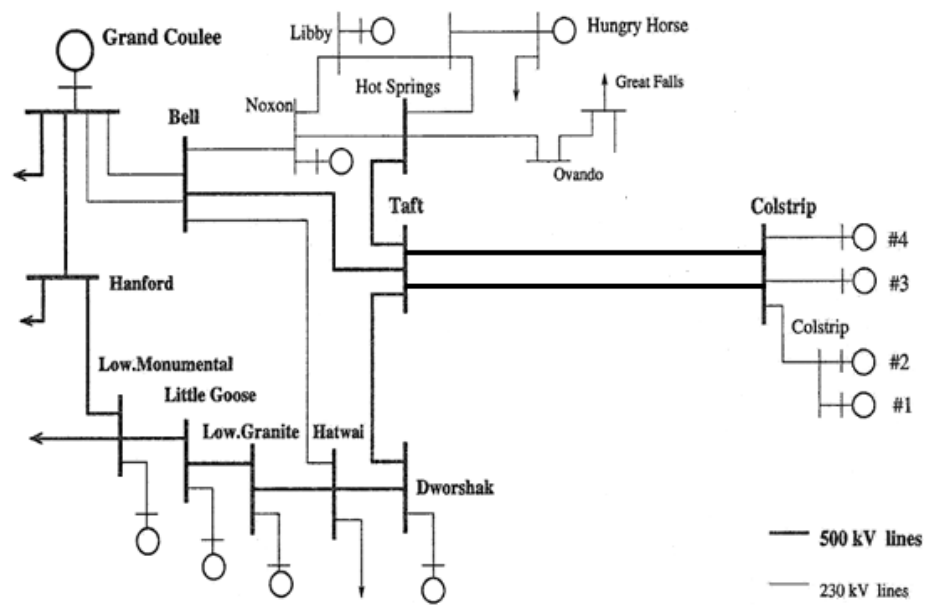

Figure 11. Montana 500kV transmission system

Firstly, the analysis of pure AC system is performed for the considered system. In case of pure AC system the loadability is evaluated considering the steady state stability margin of $30 \%$ which is the recommended stability margin for long transmission line [1]. In this case the evaluated loadability is 1028MW. The stability (CCT) of pure AC system is evaluated considering a severe most fault (3-phase to 
ground) at the Colstrip generator bus with $1028 \mathrm{MW}$ of pre-fault steady state loading and the obtained CCT is $175 \mathrm{~ms}$.

Secondly, the AC system is converted into simultaneous AC-DC system and then the developed expression, equation (21), is applied for the optimal operation of the system. In this case the loadability and stability of the system at the optimal points are evaluated considering the variation of AC and DC voltage mix and transmission angle. As the simultaneous AC-DC transmission system contains AC and DC both form of voltage in the same line it is an opportunity to operate the system by changing the magnitude of AC and DCvoltages. Moreover, this AC-DC system gives another opportunity to operate the transmission system with wide range of variation of transmission angle.

The loadability and stability improvements for the optimal operation of the simiulaneous AC-DC system are evaluated in comparison with the loadability and stability of pure AC system. The evaluated improvements in loadability and stability at the optimal operating points are presented in Table 5 considering the variation of voltage mix of AC-DC system. During the variation of AC and DC voltage mix a constant transmission angle of $44.47^{\circ}$ of AC power flow is considered.

Table 5. Improvement of Loadability and Stability at the Optimal Point for Different Voltage Mix

\begin{tabular}{ccccc} 
\% of voltage mix & $\begin{array}{c}\text { Power flow at the optimal } \\
\text { point (MW) }\end{array}$ & $\begin{array}{c}\text { Loadability } \\
\text { improvement } \\
\text { with optimal operation } \\
(\%)\end{array}$ & $\begin{array}{c}\text { Stability improvement } \\
\text { with optimal operation } \\
(\%)\end{array}$ \\
\hline $\begin{array}{c}\mathrm{V}_{\mathrm{ac}} \\
\mathrm{V}_{\mathrm{dc}}\end{array}$ & 10 & 1158 & 12.65 & 18.29 \\
80 & 20 & 1319 & 28.31 & 38.86 \\
70 & 30 & 1450 & 41.04 & 44.57 \\
60 & 40 & 1567 & 52.43 & 48.00 \\
50.5 & 49.5 & 1664 & 61.87 & 49.71 \\
\hline
\end{tabular}

It is observed that the loadability and stability improvements at the optimal points increase with the increase of DC voltage mix. The table also reveals that the rate of increase in loadability improvement is higher than that of stability improvement with the increase of DC voltage mix. At the highest point of DC voltage mix $(49.5 \%)$ the optimal operation gives $61.87 \%$ and $49.71 \%$ of loadability and stability improvements respectively. Note that, in simultaneous AC-DC system the DC voltage mix must be less than $50 \%$ of original AC voltage [15].

Table 6 presents the variation of loadability and stability improvements with the variation of transmission angle at the optimal operating points of simultaneous AC-DC system. In case of the variation of transmission angle a constant DC voltage mix of $49.5 \%$ is considered for the operation of the system. It is also found that the improvements are decreasing in nature with the increase of transmission angle. At the lowest level of transmission angle (20 degree) in the table the optimal point gives $68.48 \%$ and $57.71 \%$ of loadability and stability improvements respectively.

Table 6. Improvement of Loadability and Stability at the Optimal Point for Different Transmission Angle

\begin{tabular}{cccc}
$\begin{array}{c}\text { Power transmission } \\
\text { angle (degree) }\end{array}$ & $\begin{array}{c}\text { Power flow at the optimal } \\
\text { point }\end{array}$ & $\begin{array}{c}\text { Loadability } \\
\text { improvement } \\
\text { with optimal operation } \\
(\%)\end{array}$ & $\begin{array}{c}\text { Stability improvement } \\
\text { with optimal operation } \\
(\%)\end{array}$ \\
\hline 20 & 1732 & 68.48 & 57.71 \\
30 & 1706 & 65.95 & 54.29 \\
40 & 1678 & 63.23 & 51.43 \\
50 & 1647 & 60.21 & 48.00 \\
60 & 1613 & 56.91 & 44.57
\end{tabular}




\section{CONCLUSION}

Loadability and stability are reciprocal in nature. That is, increase in one parameter causes decrease in other parameter. Simultaneous AC-DC power flow can increase loadability and stability both at the same time but maintaining a trade-off between these two. This paper presents an analytical expression for the combined improvement of loadability and stability in case of simultaneous AC-DC system. Applying this expression in any system an optimal point can be found where loadability and stability both improvement can be achieved at a reasonable level.

Through numerical analysis it is seen that the objective function curve has a maximum point. Initially the value of the objective function increases with the increase of power flow and after reaching a certain point it starts decreasing with the increase of power flow.

The numerical analysis for different voltage and line length also clearly reveal that the optimal points shifted from lower loadability to higher loadability with the increase of voltage level while maintaining approximately constant magnitude of the improvements in loadability and stability at the optimal points. On the contrary, the optimal points shifted from higher loadability to lower loadability with the increase of line length while maintaining a significant increase in the magnitude of the loadability and stability improvements at the optimal points.

The accuracy of the developed model is extremely high which has been established in the validation section by comparing the results with the MATLAB simulation. From the application of the model it is seen that the improvements in loadability and stability at the optimal points are found in increasing and decreasing in nature with the increase of DC voltage mix and transmission angle, respectively. Note that, the impact of the change of voltage mix is much higher than the change in transmission angle on the loadability and stability improvements at the optimal points.

\section{APPENDIX}

Appendix-A

The parameters of different components of the power system considered for the numerical analysis of the proposed model is presented in Table A.

Table A. Parameters of the Different Components of Single Circuit Transmission System

\begin{tabular}{|c|c|c|}
\hline Sl. No. & Component & Parameter \\
\hline 01 & Line & $\begin{array}{l}\mathrm{z}=0.01755+\mathrm{j} 0.3292 \Omega / \mathrm{km} / \mathrm{phase} \\
\text { Single ckt, Three phase, } 60 \mathrm{~Hz}, 400 \mathrm{~km}, 345 \mathrm{kV} \text {, Thermal limit current }= \\
1.8 \mathrm{kA} \text {, ACSR twin bundle conductor }\end{array}$ \\
\hline 02 & Generator & $\begin{array}{l}\text { 1100MVA, } 24 \mathrm{kV}, 60 \mathrm{~Hz} \text {, the parameters on its own base }-\mathrm{Xd}=1.305, \mathrm{Xd}^{\prime} \\
=0.3, \mathrm{Xd}^{\prime \prime}=0.3, \mathrm{Xq}=0.474, \mathrm{Xq}^{\prime \prime}=0.243, \mathrm{X}=0.18, \text { Stator resistance } \\
\mathrm{Rs}=0.00285, \mathrm{Td}^{\prime}=1.01 \mathrm{~s}, \mathrm{Td}^{\prime \prime}=0.053 \mathrm{~s}, \mathrm{Tqo}^{\prime \prime}=0.1 \mathrm{~s}\end{array}$ \\
\hline 03 & Generator Transformer & $1100 \mathrm{MVA}, 24 / 132 \mathrm{kV}, 60 \mathrm{~Hz}, 10 \%$ reactance. \\
\hline 04 & $\begin{array}{l}\text { Transformer (At the } \\
\text { sending end of the line): }\end{array}$ & $\begin{array}{l}\Delta \text {-Y, } 1100 \mathrm{MVA}, 132 / 345 \mathrm{kV}, 60 \mathrm{~Hz}, 16 \% \text { reactance. (pure AC) } \\
\Delta \text {-Z, 500MVA, } 132 / 172.5 \mathrm{kV}, 60 \mathrm{~Hz}, 16 \% \text { reactance. (AC-DC) }\end{array}$ \\
\hline 05 & $\begin{array}{l}\text { Transformer (At the } \\
\text { receiving end of the } \\
\text { line): }\end{array}$ & $\begin{array}{l}\text { Y }-\Delta 1100 \mathrm{MVA}, 345 / 132 \mathrm{kV}, 60 \mathrm{~Hz}, 16 \% \text { reactance.(Pure AC) } \\
\mathrm{Z}-\Delta 500 \mathrm{MVA}, 172.5 / 132 \mathrm{kV}, 60 \mathrm{~Hz}, 16 \% \text { reactance (AC-DC) }\end{array}$ \\
\hline 06 & DC system & $\begin{array}{l}\text { The Rectifier and Inverter are } 12 \text {-pulse converters using two 6-pulse thyristor } \\
\text { bridges connected in series, DC current (rated) }=5.4 \mathrm{kA} \text {, Smoothing } \\
\text { reactor }=0.5 \mathrm{H}, \text { Rectifier firing angle(minimum) }=5^{0} \text {, Inverter Extinction } \\
\text { angle }(\text { minimum })=14^{0} .\end{array}$ \\
\hline
\end{tabular}

Appendix-B

For the application of the proposed model only $500 \mathrm{kV}$ double circuit transmission line from Colstrip to Taft is considered, excluding other portion of the power system [22]. Colstrip with the generation capacity of $2272 \mathrm{MW}$ is considered as an equivalent machine (generator) and Taft is considered as an infinite bus. The application also does not consider Broadview and Garrison buses in between Colstrip and Taft. The detail parameters are presented in Table B. 
Table B.The Parameters of Montana 500kV Transmission System

\begin{tabular}{|c|c|c|}
\hline Sl. No. & Component & Parameter \\
\hline 01 & Line & $\begin{array}{l}\mathrm{x}=\mathrm{j} 253.21 \Omega / \text { phase } / \mathrm{ckt} \text {, Double ckt, Three phas, } 60 \mathrm{~Hz} \text {, } \\
804 \mathrm{~km} \text { '500kV,Thermal limit current }=3 \mathrm{kA}\end{array}$ \\
\hline 02 & Generator & $\begin{array}{l}358 * 2,778 * 2(\mathrm{MW}) \\
24 \mathrm{kV}, \text { Reactance }=0.3 \mathrm{pu}, \mathrm{H}=3.5 \mathrm{~s} .\end{array}$ \\
\hline 03 & Generator Transformer & $24 / 230 \mathrm{kV}$, Leakage reactance $=0.15 \mathrm{pu}$ \\
\hline \multirow{2}{*}{04} & \multirow{2}{*}{$\begin{array}{l}\text { Transformer (At the } \\
\text { sending end of the } \\
\text { line): }\end{array}$} & $\Delta-\mathrm{Y}, 230 / 500 \mathrm{kV}$, leakage reactance $=0.1 \mathrm{pu} .($ pure $\mathrm{AC})$ \\
\hline & & $\Delta-\mathrm{Z}, 230 / 253 \mathrm{kV}$, Leakage reactance $=0.1 \mathrm{pu} .(\mathrm{AC}-\mathrm{DC})$ \\
\hline 05 & $\begin{array}{l}\text { Transformer (At the } \\
\text { receiving end of the } \\
\text { line): }\end{array}$ & $\mathrm{Z}-\Delta 253 / 500 \mathrm{kV}$, Leakage reactance $=0.1 \mathrm{pu},(\mathrm{AC}-\mathrm{DC})$ \\
\hline 06 & DC system & $\begin{array}{l}\text { DC system rated voltage and current are } 202 \mathrm{kVand} 9 \mathrm{kA} \text {, } \\
\text { respectively. }\end{array}$ \\
\hline
\end{tabular}

\section{REFERENCES}

[1] R. D. Dunlop, R. Gutman, and P. P. Marchenko, "Analytical development of Loadability Characteristics for EHV and UHV Transmission Line" IEEE Transactions on Power Apparatus and Systems, Vol. PAS-98, No. 2,pp. 606617, March/April 1979.

[2] P. Kundur, Power System Stability and control, New York: McGraw-Hill, Inc, 1994.

[3] R. Rajaraman, F. Alvarado, A. Maniaci, R. Camfildand S. Jali, "Determination of Location and Amount of Series Compensation to Increase Power Transfer Capability," IEEE Transactions on Power Systems, Vol. 13, No. 2, pp. 294-300, May 1998.

[4] E. A. Leonidaki, D. P.Georgiadis, and N. D. Hatziargyriou, "Decision Trees for Determination of Optimal Location and Rate of Series Compensation to Increase Power System Loading Margin," IEEE Transactions on Power Systems, Vol. 21 ,No. 3, pp. 1303-1310, Aug. 2006.

[5] M. Rahmani, G. Vinasco, M. J. Rider, R. Remero, and P. M. Pardalos, "Multistage Transmission Expansion Planning Considering Fixed Series Compensation Allocation," IEEE Transactions on Power Systems, Vol. 28, No. 4, pp. 3795-3805, June 2013.

[6] G. Y., Yang , G. Hovland,R.Majumder, and Z. Y. Dong, "TCSC Allocation Based on Line Flow Based Equations Via Mixed-Integer Programming," IEEE Transactions on Power Systems, Vol. 22 ,No. 4, Novemver 2007.

[7] D. N. Kosterev, W. J. Kolodziej, R. R. Mohler and W. A. Mittelstadt, "Robust Transient Stability Control Using Thyristor-Controlled Series Compensation," in Proceedings of the $4^{\text {th }}$ IEEE Conference on Control Applications, Sep. 1995, pp. 215-220 (1995).

[8] N. Johansson,L. Angquist, and H. P. Nee, "An Adaptive Controller for Power System Stability Improvement and Power Flow Control by Means of a Thyristor Switched Series Capacitor (TSSC),"IEEETransactions on Power Systems, Vol. 25, No.1, pp. 381-391, Nov. 2010.

[9] H. Rahman and B. H. Khan "Power Upgrading of Transmission Line by combining AC-DC Transmission"IEEETransactions on Power Systems, Vol. 22 ,No. 1, February 2007.

[10] P. V. K. Babu, P. B. Prasad, and M. P. Lalitha, "Power Upgrading of Transmission Line by Combining AC-DC Transmission,'International Journal of Engineering Research and Applications (IJERA), Vol. 2, No. 6, pp. 16991704, Nov./Dec. 2012.

[11] B. G. Sherkhaneand M. R. Bachawad, "Improvement in Power Transmission Capacity by Simultaneous AC-DC Transmission," The International Journal of Engineering And Science(IJES), Vol. 4, No. 5, pp. 22-31, May 2015.

[12] H. Rahman, and , B. H. Khan, "Stability Improvement of Power System by Simultaneous AC-DC Power Transmission," Electric Power System Research, Vol. 78, No. 4, pp. 756-764, Apr. 2008.

[13] K. P. Basu, and M. H. Neem, "Stability Enhancement of Power System by Simultaneous AC-DC Power transmission," IEICE Electronics Express, Vol. 6, No. 12, pp. 818-823, June 2009.

[14] T. V. Muni, T. Vinoditha, D. K. Swamy, "Improvement of Power System Stability by Simultaneous AC-DC Power Transmission" International Journal of Scientific \& Engineering Research, ISSN 2229-5518, Vol. 2, No. 4, April2011.

[15] M. T. Alam and Q. Ahsan, “A Mathematical Model for the Loadability Analysis of a Simultaneous AC-DC Power Transmission System”Electrical Engineering, Springer, Vol. 100, No. 3, pp. 1901-1911, September, 2018.

[16] M. T. Alam and Q. Ahsan "A Mathematical Model for the Transient Stability Analysis of a Simultaneous AC-DC Power Transmission System”,IEEETransactions on Power Systems, Vol. 33, No. 4, July 2018.

[17] K. P. Basu, "Stability Enhancement of Power System by Controlling HVDC Power Flow through the Same AC Transmission Line" 2009 IEEE Symposium on Industrial Electronics and Application (ISIEA 2009), October 4-6, 2009, Kuala Lumpur, Malaysia.

IJEEI, Vol. 8, No. 2, June 2020: 215 - 229 
[18] A. Somani, P. P. Chakrabarti and A. Patra, "An Evolutionary Algorithm-Based Approach to Automated Design of Analog and RF Circuits Using Adaptive Normalized Cost Functions," IEEE Transactions on Evolutionary Computation, Vol. 11, No. 3, pp. 336-353, June 2007.

[19] H. Nakayama et al., Sequential Approximate Multiobjective Optimization Using Computational Intelligence,Springer-Verlag Berlin Heidelberg, 2009.

[20] N. Srinivas and K. Deb, "Multiobjective Optimization Using Nondominated Sorting in Genetic Algorithms" Journal of Evolutionary Computation, Vol. 2, No. 3, pp. 221-248, 1994.

[21] S. Obayashi et al."FindingTradeoffs by Using Multiobjective Optimization Algorithms" Transactions of JSASS, Vol. 47, No. 155, pp. 51-58, May, 2004.

[22] D. N. Kosterev, W. A. Mittelstadt, R. R. Mohler and W. J. Kolodziej, "An Application Study for Sizing and Rating Controlled and Conventional Series Compensation” IEEE Transactions on Power Delivery, Vol. 11, No. 2, April 1996.

\section{BIOGRAPHIES OF AUTHORS}

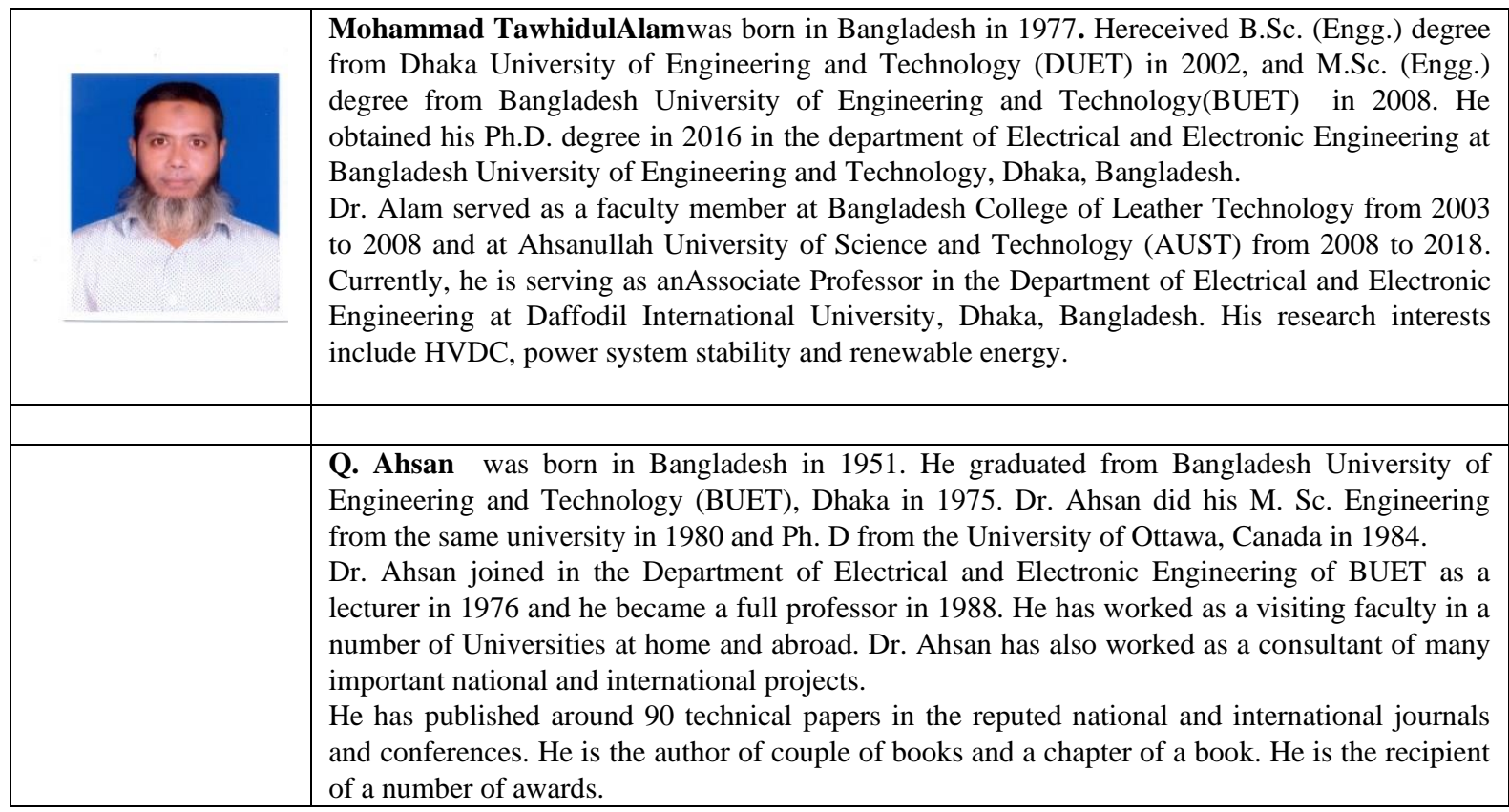

